\title{
An intensive study of aerosol optical properties in Beijing urban area
}

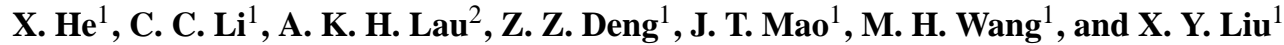 \\ ${ }^{1}$ Dept. of Atmospheric Sciences, School of Physics, Peking University (PKU), Beijing, China \\ ${ }^{2}$ ENVF/IENV, The Hong Kong University of Science and Technology (HKUST), Hong Kong, China
}

Received: 5 February 2009 - Published in Atmos. Chem. Phys. Discuss.: 8 May 2009

Revised: 8 November 2009 - Accepted: 9 November 2009 - Published: 26 November 2009

\begin{abstract}
In order to quantify the aerosol impact on climate, a range of aerosol parameters are required. In this paper, twoyear of ground-based observations of aerosol optical properties from an urban site in Beijing of China are assessed. The aerosol absorption coefficient $\left(\sigma_{a}\right)$, scattering coefficient $\left(\sigma_{s}\right)$, as well as single scattering albedo $(\omega)$ are analyzed to aid in characterizing Beijing's urban aerosol. Two-year averages (and standard deviations) for $\sigma_{a}$ at $532 \mathrm{~nm}, \sigma_{s}$ at $525 \mathrm{~nm}$ and $\omega$ at $525 \mathrm{~nm}$ are $56 \pm 49 \mathrm{Mm}^{-1}, 288 \pm 281 \mathrm{Mm}^{-1}$ and $0.80 \pm 0.09$, respectively. Meanwhile, there is a distinct diurnal variation for $\sigma_{a}$, with its minimum occurring at approximately 14:00 to $15: 00$ and maximum at midnight. $\sigma_{s}$ peaks in the late morning and the minimum occurs in the evening. $\sigma_{s}$ in summer is higher than that in winter. $\omega$ is also higher in summer than that in winter, except before 07:00 a.m., and peaks in the early afternoon. Both $\sigma_{a}$ and $\sigma_{s}$ show strong dependence on local wind in all four seasons. When the wind blows from the north with low speed $(0-2 \mathrm{~m} / \mathrm{s})$, the values of $\sigma_{a}$ are high, and in contrast, very low with wind speeds higher than $4 \mathrm{~m} / \mathrm{s}$. When the wind blows from south with low speed $(0-4 \mathrm{~m} / \mathrm{s}), \sigma_{a}$ is intermediate. The patterns of the wind dependence of $\sigma_{a}$ indicates that $\sigma_{a}$ is mainly dominated by local emissions. $\sigma_{s}$ displays a similar dependence on wind speed and direction to $\sigma_{a}$, except in summer. In summer, the $\sigma_{s}$ value is highest when wind is from southeast with speed of $0-6 \mathrm{~m} / \mathrm{s}$. This indicates that the particle pollution resulting from regional transport is only significant in the summer season. $\omega$ also shows wind dependence to some extent though not as strong as $\sigma_{a}$ or $\sigma_{s}$. Overall, the wind dependence results provide valuable information about the locations of
\end{abstract}

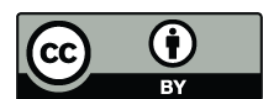

Correspondence to: $\mathrm{C}$. C. $\mathrm{Li}$ (ccli@pku.edu.cn) aerosol pollution sources and suggest that the air pollution in summer is a regional problem but in other seasons it is mainly affected by local urban emissions.

\section{Introduction}

Aerosols have been gaining substantial attention recently due to their important, yet complex role in the global climate. It is generally accepted that aerosols affect the earth's energy budget mainly through directly scattering incoming solar radiation back into space and indirectly enhancing cloud reflectivity by increasing the number concentration of cloud droplets (Penner et al., 2001; IPCC, 2001; Kaufman et al., 2002). However, their combined effect is very complicated and large uncertainties remain in the simulation of climate systems. For example, the existence of absorptive aerosols such as black carbon (BC) may lead to local heating in the atmosphere as well as absorption and re-emission of longwave infrared radiation that enhances the greenhouse effect and can then partially counteract the cooling effect of sulfate aerosols. Jacobson (2001) concluded that the warming effect of BC may nearly balance the net cooling effect of other anthropogenic aerosol constituents. BC is usually released from the combustion of fossil fuels, primarily from diesel, coal, and biomass burning. It is inert in the atmosphere as a result of its chemical structure. Generally, BC is a component of fine particle aerosols and thus can be a great threat to human health because it can be inhaled deep into the lungs. It has been reported that the $\mathrm{BC}$ aerosols can also alter precipitation, surface air temperature and large-scale circulation and hydrological cycles with significant regional climate effects (Menon et al., 2002). Single scattering albedo $(\omega)$, which is

Published by Copernicus Publications on behalf of the European Geosciences Union. 
defined as the ratio of scattering coefficient $\left(\sigma_{s}\right)$ to the total extinction coefficient, is another optical parameter that characterizes aerosol optical properties. For BC, $\omega$ is about 0.2, while nearly 1.0 for sulfate aerosol. Aerosols have a negative Top of Atmosphere (TOA) forcing when $\omega$ exceeds 0.95, and a positive TOA forcing if $\omega<0.85$, and for the intermediate values, the net effect can change from negative to positive forcing depending on cloud fraction, surface albedo, and cloud distribution (Ramanathan et al., 2001a). The $\omega$ of the aerosols in the Northern Hemisphere are in the range of 0.85 to 0.95 (Ramanathan et al., 2001b). Single scattering albedo is a key parameter in atmospheric aerosol optical depth retrieval from satellite remote sensing. A value of $\sim 0.95$ of the column averaged $\omega$ was used in the operational aerosol retrieval algorithm from Moderate Resolution Imaging Spectroradiometer (MODIS) for the urban aerosol over the whole eastern China (Kaufman et al. 1997; Chu et al. 2003). However, the improved second-generation operational algorithm adopted 0.85 for the urban aerosol over this region (Levy et al. 2007).

Beijing, one of the largest cities in the world, has been experiencing the problem of severe aerosols loading as a result of rapid economic development, population expansion and urbanization over the last 30 years (Chan et al., 2008), all of which will pose great threats to the climate (Zhou et al., 2004; Crutzen, 2004). The Air Pollution Index (API) released by the Beijing Municipal Environmental Protection Bureau indicates that the main pollutant in Beijing is respirable suspended particles (RSP or $\mathrm{PM}_{10}$ - particulate matters with diameter of $10 \mu \mathrm{m}$ or less) (http://www.bjepb.gov. $\mathrm{cn} /$ ). It was reported that the hourly average $\mathrm{PM}_{10}$ could be as high as $400 \mu \mathrm{g} \mathrm{m}^{-3}$ (Ando et al., 1994; He et al., 2001; Shi et al., 2003). The Beijing aerosol contains a high amount of black carbon, dust from construction activities, coal burning particles, factory and vehicle exhaust particles (Zhang, 1998; Bergin, 2001; He et al., 2001; van Pinxteren et al., 2009). Takegawa et al. (2009) reported that both chemical and physical properties of aerosols were significantly altered owing to secondary formation of aerosol on a regional scale after analyzing measurements in summer of 2006 in Beijing.

The impairment of visibility is one of the most notable effects of aerosol. As a key factor for evaluating atmospheric pollution, Aerosol Optical Depth (AOD) has increased dramatically from 1961 to 1990 (Luo et al., 2001). Li et al. (2003) reported a yearly mean AOD of 0.5 in Beijing. While different values of $\omega$ have been observed based on different instruments and measuring conditions in Beijing, the value of $\omega$ is comparatively low. According to one-week of surface observations made in June 1999, a low $\omega$ value of 0.81 was obtained by in situ surface observations in Beijing (Bergin et al., 2001). Qiu et al. (2004) reported that $\omega$ had decreased from $\sim 0.85$ to $<0.83$ over Beijing from 1996-2001. The $\omega$ value derived from combined one-wavelength Raman lidar and Sun photometer measurements in Beijing in January 2005 was as low as 0.75 at the wavelength of $525 \mathrm{~nm}$ and had been following a downward trend since 2001 (Müller et al., 2006). Some measurements of $\omega$ value in Beijing and other sites are listed in Table 1.

The spatial and temporal distribution of aerosols requires analysis of topography and local and regional meteorological conditions, especially wind direction (WD), wind speed (WS) and atmospheric stability. The wind plays an important role in diluting and transporting air pollutants. It determines how quickly the pollutants mix with ambient air and how fast they move away from their sources. The relationship between meteorology and air pollution has been investigated, such as, for ozone (Comrie, 1994; Eder et al., 1994), BC (Wiliam et al., 1997; Ramachandran et al., 2007) and aerosols (Elminir, 2005; Hartog, 2005). The dependence of urban aerosol optical properties on meteorology in summer in Beijing is also well investigated in some recently studies. Garland et al. (2009) conducted measurements for a month long period at a suburban site $\sim 30 \mathrm{~km}$ south of Beijing and found when the measured air masses originated in the north and passed over the Beijing urban area, the single scattering albedo was generally low, indicating that the local emissions of particulate matter in Beijing were dominated by primary particles from combustion sources (soot), and that the southerly inflow to Beijing typically had very high scattering coefficients and higher than average single scattering albedo values, suggesting a large amount of secondary aerosol (e.g. sulfate and oxidized organics). Jung et al. (2009) concluded that stagnant weather conditions with southerly wind and low wind speed accelerated the accumulation of pollutants in Beijing, which led to severe haze. $\mathrm{Nu}-$ merical simulations have suggested that the particulate pollution in Beijing originates from a combination of regional and local sources. These models have predicted that $34 \%$ of PM2.5 (Streets et al., 2007) and 37.9\% of $\mathrm{PM}_{10}$ (Chen et al., 2007) in urban Beijing had been generated by regional emissions.

Many observation studies have been based upon monthlong intensive measuring campaigns, but long-term, seasoncrossing measurements of the dependence of aerosol optical properties on meteorology and the seasonal differences of diurnal variation in Beijing, especially for aerosol single scattering albedo, were rarely reported.

This work presents the variations of absorption coefficient, scattering coefficient and single scattering albedo and examines the relationship between wind and aerosol optical properties $\left(\sigma_{a}, \sigma_{s}\right.$ and $\left.\omega\right)$ from two years' observation in Beijing. Diurnal, seasonal and annual variations are also analyzed. In Sect. 2, site, instruments and data are introduced. In Sect. 3, the diurnal variation and statistics of aerosol absorption coefficient and scattering coefficient as well as single scattering albedo are shown, and the wind dependency is analyzed. Lastly, discussion and conclusions for this study are given. 


\section{Data and methodology}

\subsection{Site descriptions}

Figure 1 presents a map, showing most of North China. The municipality of Beijing borders Hebei Province to the north, west, south, and for a small section in the east, and Tianjin Municipality to the southeast. The background image shows the yearly average of aerosol optical depth (AOD) in 2006 over the region. The data are derived from the Level 2 products (Version 5) of MODIS onboard the Terra and Aqua satellites Platform provided by the National Aeronautics and Space Administration of the United States (NASA) (http: //modis-atmos.gsfc.nasa.gov/). The contours with a value $0.4 \sim 0.5$ of AOD divide the area into two parts: a plateau and mountains in the north and plains in the south. The AOD values over the northern plateau (the blue part in the figure) are usually less than 0.4 , however, those over the North China Plain (the yellow and the red parts in the figure) are very nearly larger than 0.6 . Four main cities in this region are shown in the figure: Beijing (BJ), Tianjin (TJ), Shijiazhuang (SJZ) and Baoding (BD). Every city exhibits a higher AOD large value region (larger than 0.8 or 0.9 ).

The urban area of Beijing is located in the area bordering the North China Plain and the Inner Mongolia plateau, and is surrounded by the Taihang Mountains on the west and Yanshan Mountains on the north. Beijing is a megacity, with a population of more than 15000000 and faces severe aerosol pollution. During the period from January 2005 to December 2006, an intensive observation of aerosol optical properties was conducted at Peking University (PKU, 39 $59^{\prime} 30^{\prime \prime} \mathrm{N}$, $116^{\circ} 18^{\prime} 39^{\prime \prime} \mathrm{E}$ ), which is located in the northeastern part of the Beijing urban area. Peking University is surrounded by a number of residential and business complexes, and there are no factories nearby. As shown in Fig. 1, the sampling site (shown in the figure with a star) is on the edge of a heavily polluted region, with yearly averaged AOD values larger than 0.8. The measurement site at PKU does not have any very tall buildings nearby and therefore, the measurements reflect the average conditions over the northeastern part of the urban area of Beijing. The emitted particles in this region are mainly attributed to vehicular traffic, construction sites, cooking exhaust from families and restaurants year round, and central and domestic heating in the winter season.

\subsection{Measurements and instrumentations}

All of the instruments, including a nephelometer, an aethalometer and an automatic weather station, were located on the roof of Physics Building, approximately $30 \mathrm{~m}$ above the ground. The nephelometer and aethalometer were installed in a room built on the roof of the building with inlets over the roof of the room.

The integrating nephelometer (Model M9003, Ecotech, Australia) was used to measure the light scattering coefficient

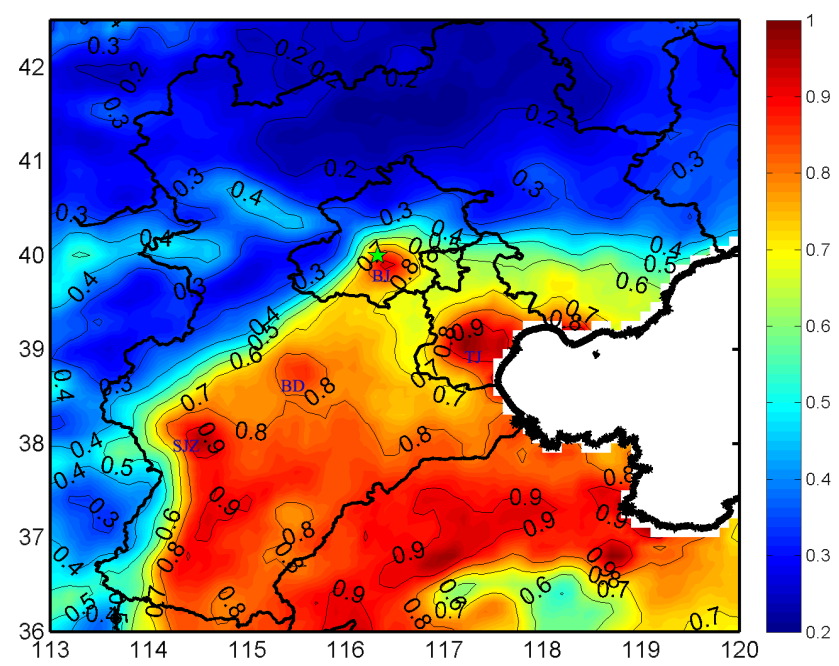

Fig. 1. Yearly mean AOD around Beijing in 2006.

at the single wavelength of $525 \mathrm{~nm}$ with scattering angles between $10^{\circ}$ and $170^{\circ}$, and no size-selective inlet was used. The measured values were automatically adjusted in realtime for different air density in a fixed airflow volume by on-board temperature and pressure sensors. A background (zero) calibration was performed at midnight everyday automatically. The span calibration was made at intervals of 10-30 days using particle-free gas. If there was a big deviation arising in zero and span calibrations, a full calibration was executed. The particle inlet had a processor-controlled automatic heater and a relative humidity (RH) threshold of $60 \%$ was set to prevent liquid particles going into the optical cell of the instrument, therefore, the RH in the measurement tube of the nephelometer ranges from 0-60\%.

An aethalometer (Model AE16, Magee Scientific, USA) was used to measure the concentration of black carbon and the absorption coefficient. The aethalometer measured the attenuation of a beam of light transmitted through the sample collected on the quart fiber filter while the filter was continuously collecting samples. The measured attenuation is linearly proportional to the mass of black carbon in the filter deposit. The instrument operated at a flow rate of $3 \mathrm{~L} / \mathrm{min}$ and in the near-infrared at a wavelength of $880 \mathrm{~nm}$, which is affected less by other non-absorbing aerosols. The drawback arises that multiple scatterings within the fiber filter do not completely overcome the scattering interference with measurements and additionally that the particles on the filter are not in their natural condition (Mao et al., 2006). Data were recorded as concentration of black carbon in $\mu \mathrm{g} \mathrm{m}^{3}$. According to the comparison result between an aethalometer at the wavelength of $880 \mathrm{~nm}$ and a photoacoustic spectrometer (PAS, an instrument which provides highly sensitive absorption measurements without interference by scattering signals) operating at $532 \mathrm{~nm}$ in South China (The Aethalometer 


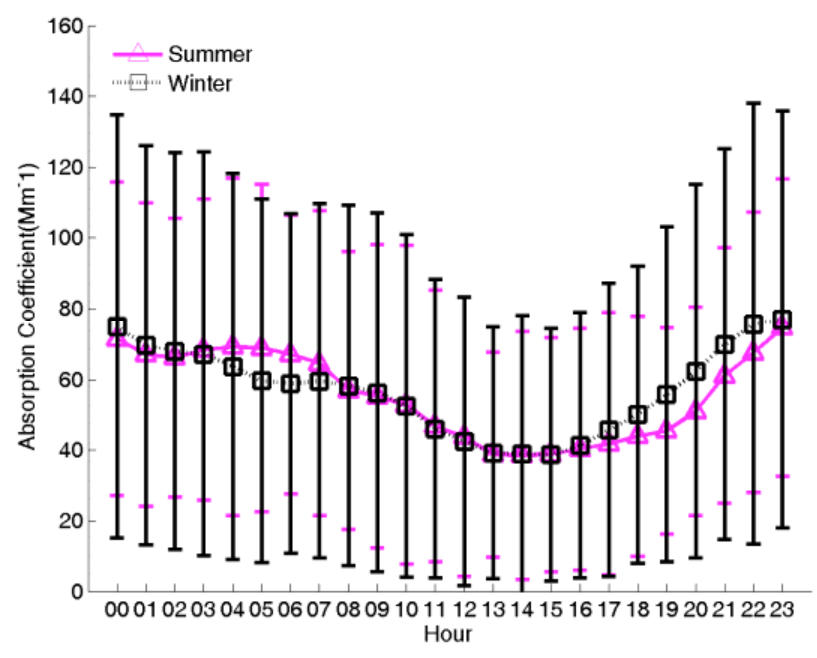

Fig. 2. Diurnal variation of absorption coefficient in summer and winter.

Handbook, 2005), there is a good agreement between the absorption coefficient $\left(\sigma_{a}, \mathrm{Mm}^{-1}\right)$ and black carbon concentration ([BC], $\left.\mu \mathrm{g} \mathrm{m}^{3}\right)$ :

$\sigma_{a}=8.28 \times[\mathrm{BC}]+2.23, R^{2}=0.92$,

where 8.28 is the conversion factor in $\mathrm{m}^{2} \mathrm{~g}$. Different values of this factor have been adopted at different sites, e.g. $10 \mathrm{~m}^{2} \mathrm{~g}$ often used for urban aerosols (Moosmuller, 1998), $8-10 \mathrm{~m}^{2} \mathrm{~g}$ (at $550 \mathrm{~nm}$ ) in Mexico City (Barnard, 2005), $8.5 \mathrm{~m}^{2} \mathrm{~g}$ from BRAVO (Big Bend Regional Aerosol and Visibility Observation Study) (Arnott, 2003). The conversion factor $8.28 \mathrm{~m}^{2} \mathrm{~g}$ was also used in a study by Yan et al. (2008) for obtaining the aerosol absorption over a rural site in North China. Lacking a comparison for Beijing at the same period to our study, we took $8.28 \mathrm{~m}^{2} \mathrm{~g}$ as the conversion factor at a wavelength of $532 \mathrm{~nm}$. From the above references we know this factor may introduce 10-20\% error to the estimation of aerosol absorption coefficients. For an average estimate, when the mean scattering coefficient is $288 \mathrm{Mm}^{-1}$, and absorption coefficient is $56 \mathrm{Mm}^{-1}$, in our study, the uncertainty (10-20\%) of the conversion factor will introduce a $1 \sim 3 \%$ error of the single scattering albedo. This error is significantly less than the current uncertainty in climate modeling or aerosol satellite retrieval of $\omega$.

Meteorological data were obtained every $12 \mathrm{~s}$ from an automatic weather station made by Vaisala Ltd., which measured wind speed, wind direction and other parameters such as relative humidity $(\mathrm{RH})$, precipitation and barometric pressure.

All of the scattering and absorption coefficient data were recorded at 5-min intervals. The data was manually edited to remove invalid data resulting from instrumental problems or when affected by dust storms or precipitation.
Single scattering albedo is defined as the ratio of the scattering coefficient to the total extinction coefficient, which is the sum of scattering coefficient and absorption coefficient

$\omega(\lambda)=\sigma_{s}(\lambda) /\left(\sigma_{s}(\lambda)+\sigma_{a}(\lambda)\right)$.

The scattering coefficient was observed at $525 \mathrm{~nm}$ and the absorption coefficient was obtained at $532 \mathrm{~nm}$. As the absorption coefficient is not sensitive to the small variation of wavelength $(532-525 \mathrm{~nm})$, the results of single scattering albedo in this study are at $525 \mathrm{~nm}$.

\section{Results and discussion}

\subsection{Absorption coefficient}

In Fig. 2 the averaged diurnal variation of $\sigma_{a}$ in summer and winter, obtained at Beijing during 2005-2006, is plotted with one standard deviation as error bars. As can be seen from the figure, the absorption coefficient exhibits strong diurnal variations both in summer and winter, with higher values at night and lower values during the day. In the early morning, the 2year mean absorption coefficient is about $75 \mathrm{Mm}^{-1}$ (inverse mega-meter: $10^{-6} \mathrm{~m}^{-1}$ ). The lowest $\sigma_{a}, 37 \mathrm{Mm}^{-1}$, occurs in the afternoon (14:00-15:00), and is only half the value at the mid-night. Note that, in general, the black carbon mainly comes from incomplete combustion of fuels, especially diesel. Heavy trucks which produce a large amount of $\mathrm{BC}$ are only permitted to pass through the urban areas of Beijing from 19:00 to 07:00. Meanwhile, aerosol concentration is also dependent on the stability of the boundary layer, which is usually unstable in the daytime and stable at night. The Beijing urban boundary layer also showed a diurnal pattern with low height values at night and much higher values during the daytime (Benjamin et al., 2006). The diurnal pattern of the absorption particles is consistent with some previous campaign observations. Van Pinxteren et al. (2006) found that the elemental carbon (EC) mass concentration showed a nighttime maximum in Beijing and attributed this both to heavy-duty trucks that were permitted to enter the city only during night and to the low inversion layer at nighttime. Garland et al. (2009) reported that the diurnal cycles of normalized absorption coefficients were characterized by near-constant values during the night, a minimum around midafternoon (14:00-16:00 Local Time - LT), and a peak in the morning ( 05:00-08:00 LT). In addition to the boundary layer dilution effect, they also hypothesized that the pattern is due to an increase in emission or specifically an accumulation of absorbing particles.

Annual mean $\sigma_{a}$ is $58 \pm 52 \mathrm{Mm}^{-1}$ in 2005 (Table 2), which is a little higher than that in 2006 , which had a value of $53 \pm 46 \mathrm{Mm}^{-1}$. The result in winter $\left(58 \pm 57 \mathrm{Mm}^{-1}\right)$ is higher than in summer $\left(54 \pm 40 \mathrm{Mm}^{-1}\right)$. This annual mean result is two-fifths lower than Bergin's (2001) surface observation in June 1999 in Beijing, and is two times larger than that 
Table 1. Aerosol optical properties made at different sites.

\begin{tabular}{|c|c|c|c|c|c|c|}
\hline site & period & $\omega$ & $\sigma_{a}\left(\mathrm{Mm}^{-1}\right)$ & $\sigma_{S}\left(\mathrm{Mm}^{-1}\right)$ & instrumentation & reference \\
\hline PKU, Beijing & 1 week June 1999 & $\begin{array}{l}0.81 \pm 0.08 \\
\quad(550)\end{array}$ & $\begin{array}{c}83 \pm 40 \\
(565)\end{array}$ & $\begin{array}{c}488 \pm 40 \\
(530)\end{array}$ & $\begin{array}{l}\text { PSAP } \\
\text { Nephlometer }^{1}\end{array}$ & $\begin{array}{l}\text { Bergin et al. } \\
(2001)\end{array}$ \\
\hline IAP, Beijing & $\begin{array}{l}2001.03-05 \\
2002.04-2004.10\end{array}$ & $\begin{array}{l}\sim 0.90 \\
(440)\end{array}$ & I & l & $\begin{array}{l}\text { AERONET } \\
\text { CIMEL radiometer }\end{array}$ & Xia et al. (2006) \\
\hline Beijing & 1993-2001 & $\begin{array}{c}0.851-0.803 \\
(550)\end{array}$ & l & l & $\begin{array}{l}\text { Pyrheliometer } \\
\text { pyranometer }\end{array}$ & Qiu et al. (2003) \\
\hline $\begin{array}{l}\text { SDZ, } \\
\text { Beijing(rural) }\end{array}$ & $2003.09-2005.01$ & $\begin{array}{l}0.88 \\
(525)\end{array}$ & $\begin{array}{c}17.54 \pm 13.44 \\
(525)\end{array}$ & $\begin{array}{c}174.6 \pm 189.1 \\
(525)\end{array}$ & $\begin{array}{l}\text { AE31 } \\
\text { Nephelometer }\end{array}$ & Yan et al. (2008) \\
\hline Beijing & 2003.06 & $\begin{array}{l}\sim 0.89 \\
(550)\end{array}$ & / & l & $\begin{array}{l}\text { AERONET } \\
\text { CIMEL radiometer }\end{array}$ & Eck et al. (2005) \\
\hline $\begin{array}{l}\text { Beijing } \\
\text { (rural) }\end{array}$ & 2005.03 & $0.81-0.85$ & $\begin{array}{c}65 \pm 75 \\
(550)\end{array}$ & $\begin{array}{c}468 \pm 472 \\
(550)\end{array}$ & $\begin{array}{l}\text { PSAP } \\
\text { Nephelometer }\end{array}$ & Li et al. (2007) \\
\hline $\begin{array}{l}\text { Beijing } \\
\text { (rural) }\end{array}$ & $\begin{array}{l}2006.08 .11- \\
2006.09 .09\end{array}$ & $0.86 \pm 0.07$ & $\begin{array}{l}51.8 \pm 36.5 \\
\quad(532)\end{array}$ & $\begin{array}{l}361 \pm 295 \\
\quad(550)\end{array}$ & $\begin{array}{l}\text { PAS } \\
\text { Nephelometer }\end{array}$ & Garland et al. (2009) \\
\hline PKU, Beijing & 2005.01-2006.12 & $\begin{array}{l}0.80 \pm 0.09 \\
\quad(525)\end{array}$ & $\begin{array}{c}56 \pm 49 \\
(532)\end{array}$ & $\begin{array}{l}288 \pm 281 \\
\quad(525)\end{array}$ & $\begin{array}{l}\text { AE16 } \\
\text { Nephelometer }^{2}\end{array}$ & Our work \\
\hline Hisar, India & 2004.12 & $\begin{array}{l}0.88 \\
(500)\end{array}$ & / & l & OPAC & $\begin{array}{l}\text { Ramachandran } \\
\text { et al. (2006) }\end{array}$ \\
\hline $\begin{array}{l}\text { Gosan, } \\
\text { South Korea }\end{array}$ & 2001.11 & $\begin{array}{l}0.88 \pm 0.02 \\
\quad(550)\end{array}$ & I & I & & Kim et al. (2005) \\
\hline $\begin{array}{l}\text { La Merced, } \\
\text { Mexico City }\end{array}$ & $\begin{array}{l}1997.02 .28- \\
1997.03 .10\end{array}$ & $0.72 \pm 0.08$ & $\begin{array}{c}80.8 \pm 31.9 \\
(880)\end{array}$ & $225.3 \pm 132.8$ & $\begin{array}{l}\text { AE- } 16^{4} \\
\text { Nephelometer }\end{array}$ & Silvia (2002) \\
\hline
\end{tabular}

${ }^{1}$ Radiance Research nephelometer M903

2 integrating Nephelometer (Model M9003, EcoTech, Australia)

3 Aethalometer (Model AE31, Magee Scientific, USA)

4 Aethalometer (Model AE16, Magee Scientific, USA)

5 NGN-2 open-air integrating Nephelometer (Optec Inc)

observed levels in rural Beijing (Yan et al., 2008) (Table 1). Both the annual and summer result in our study is higher than the summer campaign result $\left(51.8 \pm 36.5 \mathrm{Mm}^{-1}\right)$ at a suburban site in Beijing reported by Garland et al. (2009).

As seen in Table 2, the seasonal mean of $\sigma_{a}$ in winter and autumn is higher than that in spring and summer. In addition to the different dilution conditions resulting from the different mixing layer heights in summer and winter, the use of domestic and commercial heating in winter from November to March contributes to $\mathrm{BC}$ concentration by direct emissions from coal consumption.

Figure 3 presents the wind dependence of the absorption coefficient for different seasons. In this work, March, April and May is regarded as spring; June, July and August as summer; September, October and November as autumn; December, January and February as winter. In the figure, a polar coordinate system is plotted depending on the wind speed
$(0-8 \mathrm{~m} / \mathrm{s})$ and wind direction $\left(0^{\circ}-360^{\circ}\right)$. The color on the plot represents the magnitude of the variable (absorption coefficient), and the unit of the color bar is $\mathrm{Mm}^{-1}$. A direction angle $0^{\circ}$ signifies that the wind blows from the north, $90^{\circ}$ means the wind is from the east, etc. Hourly data are used in the plot. Figure 3a-d are for spring, summer, autumn and winter respectively. The black line represents the relative occurrence frequency of wind direction. We define an absorption coefficient value larger than $60 \mathrm{Mm}^{-1}$ as a "high value", larger than $40 \mathrm{Mm}^{-1}$ and less than $60 \mathrm{Mm}^{-1}$ as an "intermediate value" and less than $40 \mathrm{Mm}^{-1}$ as a "low value". We can see that there are three different $\sigma_{a}$ regions. It is clear that when wind comes from north with high speed $(>4 \mathrm{~m} / \mathrm{s}$, long distance transport), $\sigma_{a}$ is very low. This result indicates that regional transport from the far north usually provides a clean air mass to Beijing. However, when the wind blows from the same direction at low WS $\left(0-2 \mathrm{~m} / \mathrm{s}\right.$, local emission), the $\sigma_{a}$ 
(a)

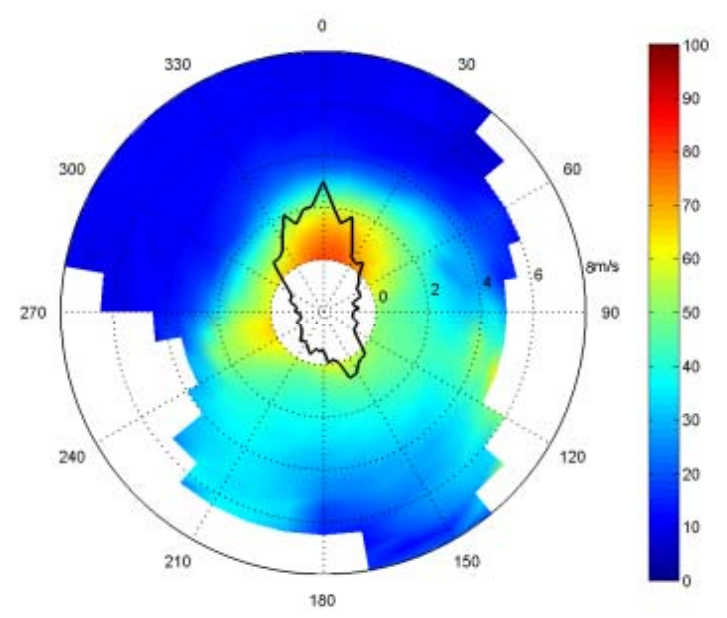

(c)

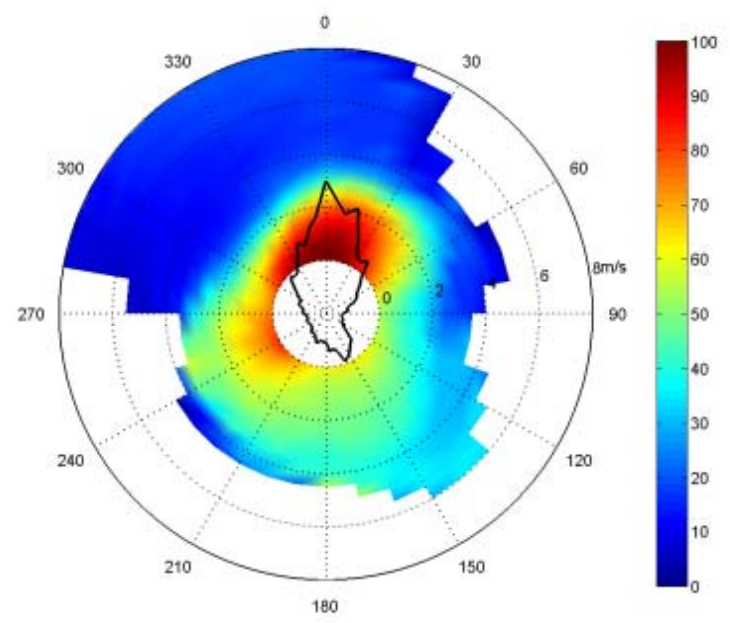

Fig. 3. Wind dependence of absorption coefficient.

value is highest. This indicates that heavy primary emissions are local, relatively close and to the north of the observation site. When the wind is from south it generally brings an intermediate value.

In spring, the $\sigma_{a}$ high values are in the WD sector from $330^{\circ}$ to $60^{\circ}$. However, in summer, the high value region moves into the sector of $300^{\circ}$ to $30^{\circ}$, and there are large areas with intermediate values. In autumn, the high $\sigma_{a}$ values appear in the sector extending from $210^{\circ}$ to $60^{\circ}$, a much wider region. While in winter, the high $\sigma_{a}$ region is focused on the region from $240^{\circ}$ to $60^{\circ}$ with low WS $(0-2 \mathrm{~m} / \mathrm{s})$, and the highest value is much higher than the other seasons. The seasonal variation of the patterns of the highest absorption (b)

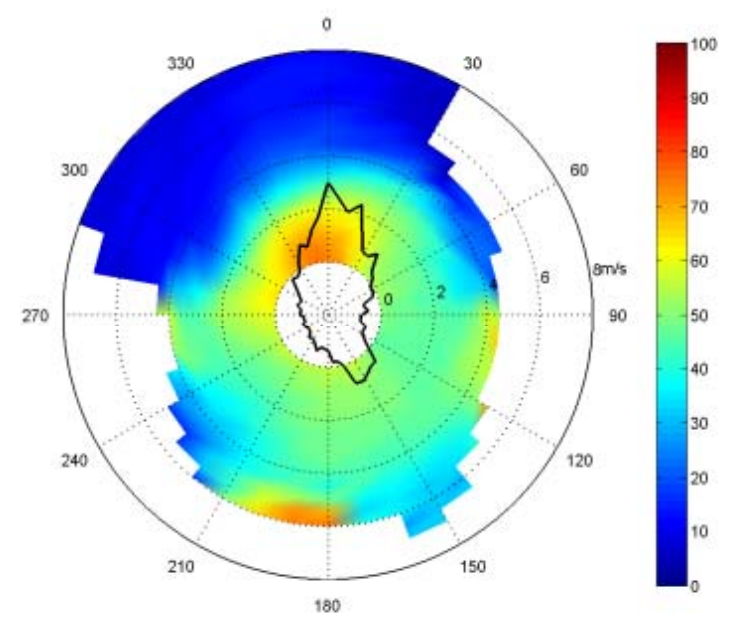

(d)

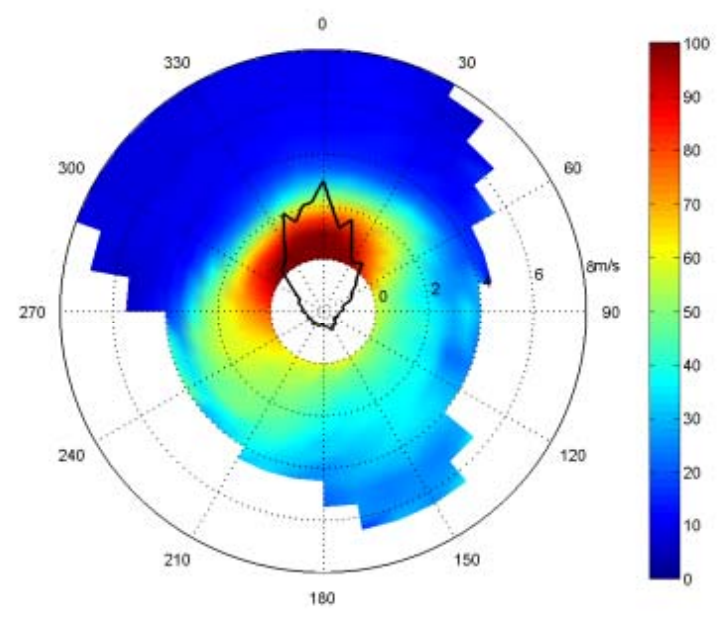

coefficients is possibly associated with the change of distribution of the key emission sources, and the similarity of patterns for the four seasons indicates that the primary BC particles are from local combustion sources for the whole year.

\subsection{Scattering coefficient}

As shown in Fig. 4, diurnal variations of $\sigma_{s}$ have the same pattern in summer and winter, both having peaks both around 10:00 a.m. and at mid-night. However, the maximal value occurs around 10:00 in summer, and at mid-night in winter. The $\sigma_{s}$ value in summer is larger than the value in winter at every hour of a day. Furthermore, the diurnal range is larger 


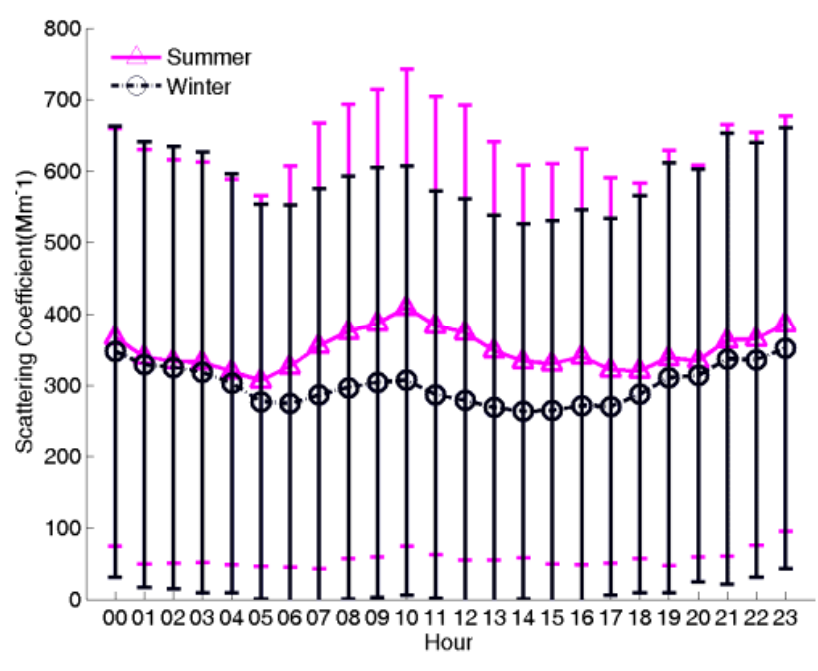

Fig. 4. Diurnal variation of scattering coefficient in winter and summer.

in summer, and the peak in the morning is much sharper and higher in summer than in winter. The $\sigma_{s}$ peaks in morning may be attributed to large emission of aerosol in the rush hour and the production of secondary aerosols with the increasing solar radiation and temperature. The fact that the significant morning peak does not appear in the diurnal pattern of the absorption coefficients indicates that the peak is more associated with the secondary formation process. Because of the stronger solar radiation and higher temperatures in summer, the morning peak at 10:00 LT is more significant in summer than in winter. The smaller difference at nighttime in winter and in summer also provides evidence that the significant difference at daytime is due to stronger secondary formation.

Higher relative humidity allows more water vapor to be picked up by the hygroscopic component, resulting in increased particle size and $\sigma_{s}$ (Nessler et al., 2005). The RH threshold in the nephelometer was set to $60 \%$, as described above, thus the humidity effect can be discounted in the significant daytime difference between summer and winter. Malm et al. (2001) reported on experiments regarding the hygroscopic properties of ambient aerosol, and found that when RH increased from $20 \%$ to $60 \%$, the increasing factor $\mathrm{f}(\mathrm{RH})$ at two sites in the United States changed from 1.00 to 1.21 or 1.38. Yan et al. (2009) reported the increasing factor, $\mathrm{f}(\mathrm{RH}=55 \%-60 \%)$, was only about 1.07 in winter over an urban area of Beijing, and also suggested a similar factor in summer (personal communication). Thus, the large difference of seasonal average results of scattering coefficients from the nephelometer $\left(351 \pm 294 \mathrm{Mm}^{-1}\right.$ in summer and $259 \pm 284 \mathrm{Mm}^{-1}$ in winter, see Table 2) should primarily be attributed to a stronger contribution from secondary formation in summer with potentially a slight effect from changing RH.
Table 2. The averages of aerosol adsorption, scattering coefficient and single scattering albedo.

\begin{tabular}{lccc}
\hline period & $\sigma_{a}\left(\mathrm{Mm}^{-1}\right)$ & $\sigma_{s}\left(\mathrm{Mm}^{-1}\right)$ & $\omega$ \\
\hline Spring & $45 \pm 39$ & $243 \pm 255$ & $0.81 \pm 0.10$ \\
Summer & $54 \pm 40$ & $351 \pm 294$ & $0.82 \pm 0.11$ \\
Autumn & $67 \pm 53$ & $311 \pm 280$ & $0.78 \pm 0.09$ \\
Winter & $58 \pm 57$ & $259 \pm 284$ & $0.79 \pm 0.06$ \\
$2005-2006$ & $56 \pm 49$ & $288 \pm 281$ & $0.80 \pm 0.09$ \\
2005 & $58 \pm 52$ & $264 \pm 279$ & $0.78 \pm 0.11$ \\
2006 & $53 \pm 46$ & $310 \pm 281$ & $0.82 \pm 0.07$ \\
\hline
\end{tabular}

Since mixing layer height (MLH) varies with surface temperature, the basic diurnal variation trend of $\sigma_{s}$ can be partly explained by changes in the MLH. From 10:00 LT to 14:00 LT, afternoon time, the decreasing trend of scattering coefficients is likely due to the increasing MLH. In winter the MLH is usually very lower in Beijing, so the aerosols have a limited space to disperse and potentially maintain a higher concentration than in summer. With the additional secondary formation in summer, even through MLH has a better dilution effect, the mean $\sigma_{s}$ is still much higher than in winter.

The patterns of diurnal cycles noted are generally consistent with previous studies. Li et al. (2007) reported that aerosol scattering coefficients, as well as absorption coefficients all have maxima during the local morning rush hour and minima during the local afternoon hours as measured in situ in March 2005 at a rural site $\sim 70 \mathrm{~km}$ southeast of Beijing. Garland et al. (2009) reported similar results about the diurnal pattern but found a slight increasing trend during 08:00-10:00 LT in their analysis of scattering coefficients.

The two-year mean $\sigma_{s}$ value is $288 \pm 281 \mathrm{Mm}^{-1}$ (Table 2) but the $\sigma_{s}$ in $2006\left(310 \pm 281 \mathrm{Mm}^{-1}\right)$ is significantly larger than that in $2005\left(264 \pm 279 \mathrm{Mm}^{-1}\right)$. Although significant effort and resources were devoted to solve the aerosol pollution in Beijing, $\sigma_{s}$ has still increased slightly. This can be attributed to the fast economic growth, e.g. the increase in vehicular traffic year after year. Weather systems are another factor which can notably affect $\sigma_{s}$. From our wind analysis, the frequency of wind with speed $(>8 \mathrm{~m} / \mathrm{s})$ in 2005 is larger than in 2006. Additionally, the frequency of precipitation in 2005 is also higher than that of 2006. Stronger wind and more precipitation may help eliminate pollutants. Seasonal variations are shown in Table 2, with higher values in summer and autumn than in spring and winter, the maximum occurs in summer. Compared with other observations, our result in summer $\left(351 \pm 294 \mathrm{Mm}^{-1}\right)$ is lower than the value of $488 \pm 370 \mathrm{Mm}^{-1}$ obtained in Beijing in June 1999 (Bergin, 2001) (Table 1) and similar to the value of $361 \pm 295 \mathrm{Mm}^{-1}$ found in the summer of 2006 at a suburban site in Beijing (Garland et al., 2009). The result in spring $\left(243 \pm 255 \mathrm{Mm}^{-1}\right)$ 
(a)

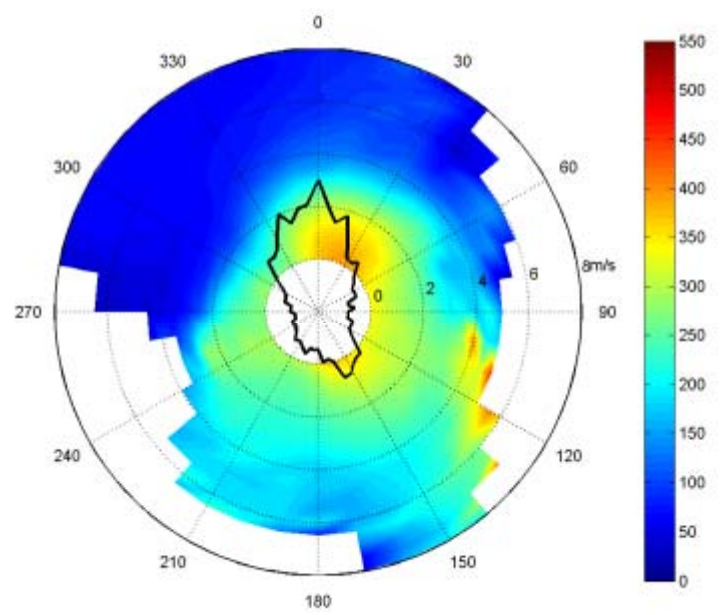

(c)

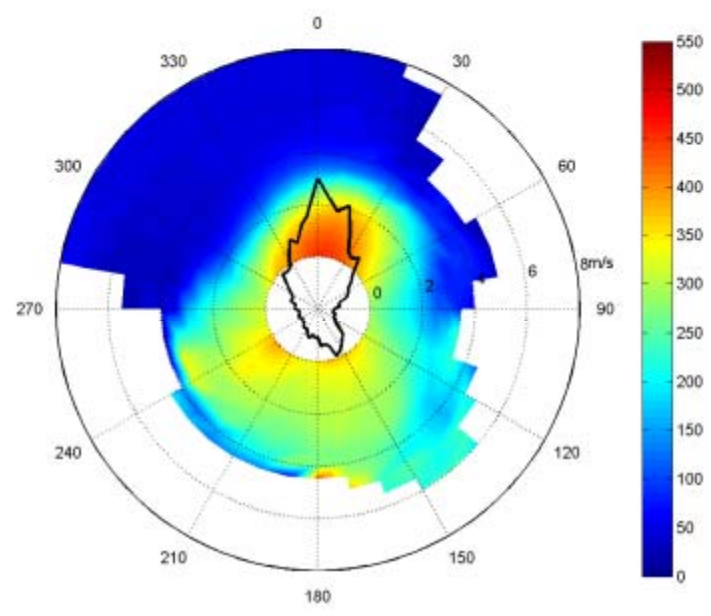

Fig. 5. Wind dependence of scattering coefficient.

is nearly two times of that in rural Beijing (Yan et al., 2008), but comparable with Silvia's (2002) observation in Mexico City.

Figure 5 presents the wind dependence of scattering coefficient. The definitions of the figure are similar to Fig. 3 with the exception that the color on the plot represents the magnitude of the scattering coefficient. Figure 5a-d are for spring, summer, autumn and winter respectively. It is clear that when the wind blows from north or northwest with high speed $(>4 \mathrm{~m} / \mathrm{s}), \sigma_{s}$ is very low. This indicates that the regional transport from north provides a clean air mass. Conversely, when the wind blows from the north with low speed $(0$ $2 \mathrm{~m} / \mathrm{s}$ ), the $\sigma_{s}$ is high, corresponding to severe air pollution (b)

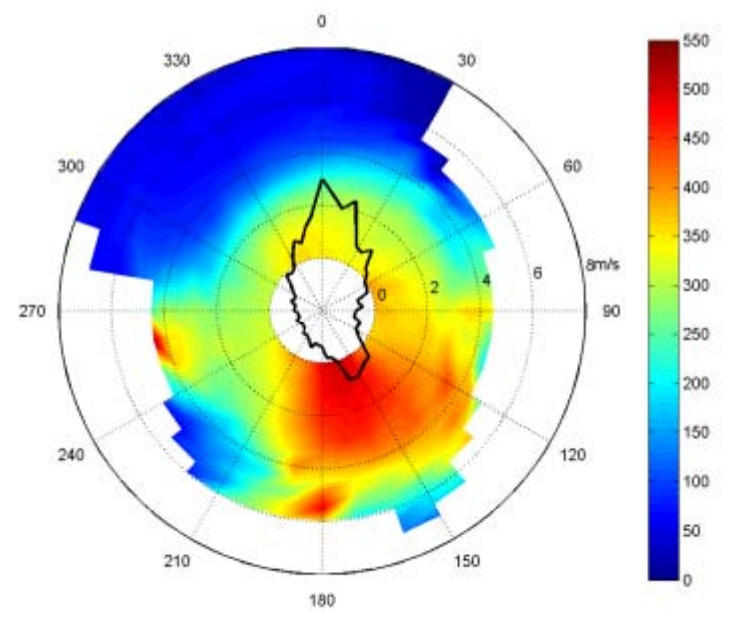

(d)

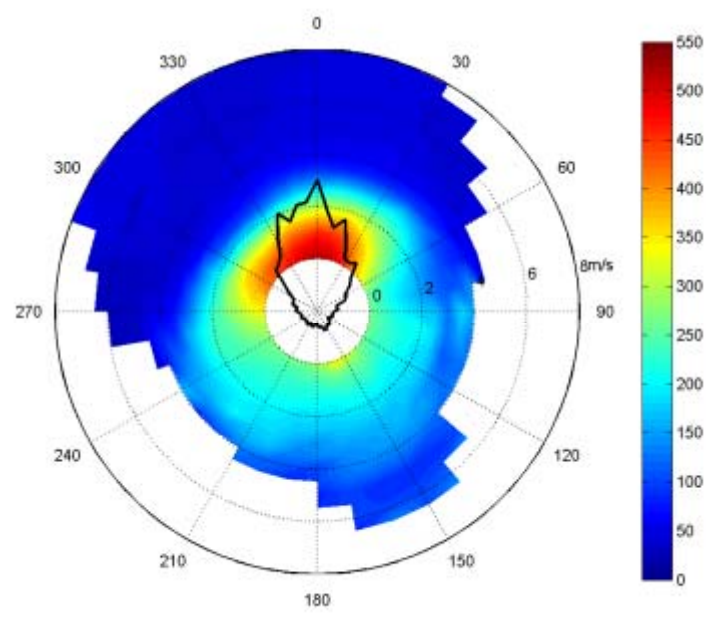

dominated by strong local emissions. However, there exists some difference among the four seasons. In spring, the large value of $\sigma_{s}$ appears in the WD sector from $0^{\circ}$ to $60^{\circ}$ with a WS of $0-2 \mathrm{~m} / \mathrm{s}$, while in summer, the highest value region moves to the sector of $90^{\circ}$ to $200^{\circ}$ with a WS of $0-6 \mathrm{~m} / \mathrm{s}$, not only a wider region but a wholly different direction when compared with spring. Also, the highest $\sigma_{s}$ value in summer is larger than in spring. In autumn, the high $\sigma_{s}$ values appear in the sector from $330^{\circ}$ to $60^{\circ}$ with a speed of $0-2 \mathrm{~m} / \mathrm{s}$. In winter, the high $\sigma_{s}$ region is only focused on the small region from $270^{\circ}$ to $30^{\circ}$. Many recent studies have concluded that the air pollution problem in Beijing is largely a regional problem, with a majority of the particle pollution in Beijing is 
transported into the city from the south (Garland et al., 2009). Southerly, low speed wind accelerated the accumulation of pollutants in Beijing, leading to severe haze conditions (Jung et al., 2009). These studies are mainly based on one-month campaign observations in summer. However, from our analysis using the circular map of the scattering coefficients to consider wind dependency, with two-year observation data, it is obvious that the wind direction dependence of scattering coefficients has very different pattern in summer compared with in other seasons. In summer the air pollution in Beijing is attributed to local emissions and regional transports from south or southeast directions, but in other seasons, the air pollution problem in Beijing is principally dominated by local emission.

\subsection{Single scattering albedo}

As shown in Fig. 6, there are similar $\omega$ variations in summer and winter, both of which peak around 14:00 and then decrease to a minimum before the sunrise. However, the minima in summer appears earlier (05:00) than in winter (07:00), and the $\omega$ increases faster in summer than in winter. This diurnal pattern corresponds to the enhancement of the scattering coefficient and the decrease of the absorption coefficient in the morning. The diurnal range of $\omega$ in summer $(0.75 \sim 0.85)$ is wider than that in winter $(0.77 \sim 0.83)$. The mean $\omega$ values in winter are generally smaller than in summer, except for early morning (00:00-7:00) values. This indicates that during 00:00-07:00 the particles in summer are more absorptive than winter, but are less absorptive from 08:00-24:00. The standard deviation in summer is also larger than in winter.

As shown in Table 2, the yearly mean $\omega$ value in 2006 is $0.82 \pm 0.07$, which is higher than that in $2005(0.78 \pm 0.11)$, mainly because of the increase of $\sigma_{s}$. The two-year mean $\omega$ value is $0.80 \pm 0.09$. Our result is similar with the result of Bergin (2001) at an urban site in Beijing, lower than the column result 0.9 at the wavelength of $440 \mathrm{~nm}$ from 33 months of AERONET data (Xia, 2006) (Table 1) and lower than the result (0.86 \pm 0.07$)$ from CAREBeijing-2006 (Garland et al., 2009) observed at a suburban site near Beijing. Qiu (2004) pointed out that the $\omega$ decreased from 0.851 to 0.803 in Beijing over the period from 1993-2001. Eck (2005) reported that $\omega$ at $550 \mathrm{~nm}$ in Beijing was 0.89 during 2001-2003 and saw a decrease since 2001 .

Figure 7 displays the wind dependence of single scattering albedo. The definitions of the figure are similar to Fig. 3 except that the color on the plot represents the magnitude of the single scattering albedo. Figure $7 \mathrm{a}-\mathrm{d}$ are for spring, summer, autumn and winter respectively. It can be seen that, in spring (Fig. 7a), when the wind blow from the southeast, the $\omega$ value is high. Meanwhile, when the wind is from the northwest with low speed $(0-4 \mathrm{~m} / \mathrm{s}$, local emission), the value of $\omega$ is low. However, for the same direction if the wind speed is high (remote transport) the $\omega$ will be larger. We can

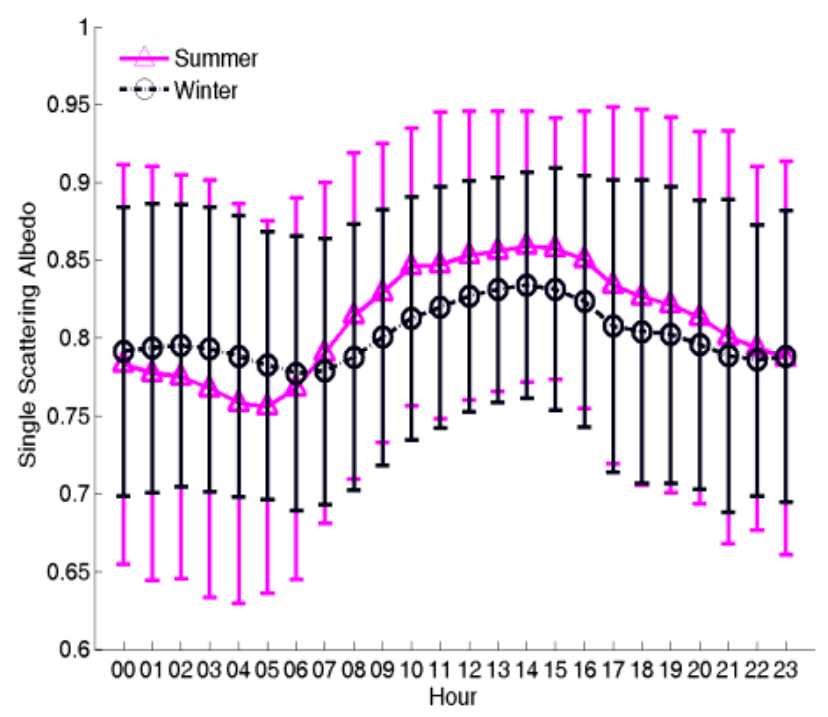

Fig. 6. Diurnal variation of single scattering albedo in summer and winter.

also see that a high $\omega$ value appeared for southeast wind with low wind speed in summer (Fig. 7b), likely due to the high value of the scattering coefficients. When the wind blows from north, however, the $\omega$ shows a much lower value. The pattern in autumn (Fig. 7c) is similar with that of summer, with a high $\omega$ value for southeast wind and a low value for northwest wind. In winter (Fig. 7d), there are no obvious differences for differing wind directions and speeds. We can see, however, that remote transport by northwesterly wind will provide a higher $\omega$ from regional transport than the one from stagnant weather conditions.

Figure 8 shows the time series of two sectors selected from the polar coordinates. The red line represents the sector with WD between $120^{\circ}$ and $180^{\circ}$ and with WS of $0-4 \mathrm{~m} / \mathrm{s}$. The black line represents the WD sector between $300^{\circ}$ and $360^{\circ}$ with the same wind speed. Monthly averages are derived from the hourly data which falls into the specific sectors. As can be seen in the figure, the red line is always above the black line and clearly illustrates the dependence of $\omega$ on wind direction; when the local wind direction is from $120^{\circ}-180^{\circ}$ (with $0-4 \mathrm{~m} / \mathrm{s}$ wind) the particles are less absorptive than those when the local wind direction is from $300^{\circ}-360^{\circ}$ (with $0-4 \mathrm{~m} / \mathrm{s}$ wind). Combining with the wind dependency maps of absorptions (Fig. 3) and scattering coefficients (Fig. 4), the figure indicates that local sources with more severe combustion emissions are likely located to the north or northwest of the observation site.

\section{Discussion and conclusions}

In this paper, we present results from a two-year aerosol ground-based observation in Beijing, a heavily polluted 
(a)

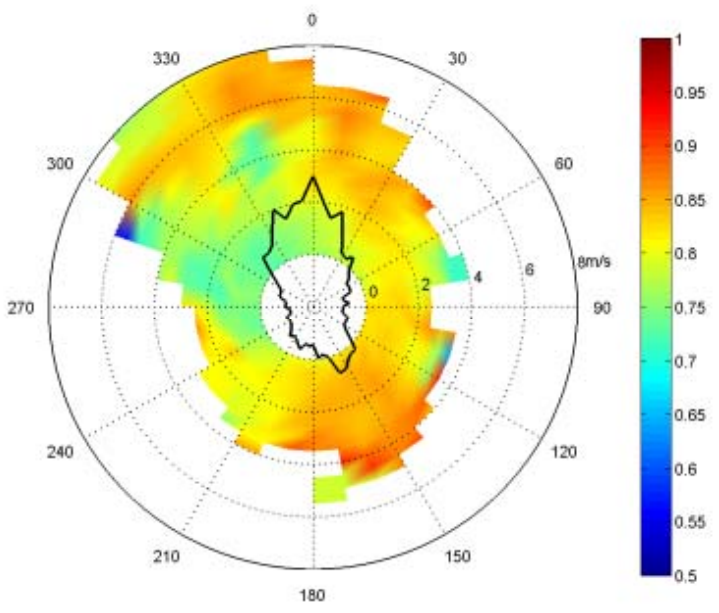

(c)

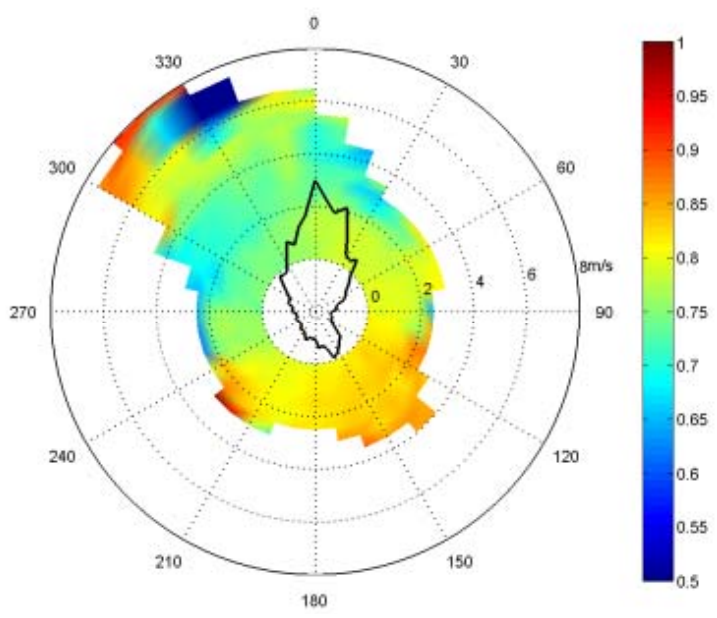

Fig. 7. Wind dependency of single scattering albedo.

megacity. Based on the 24 months' data, three important parameters, $\sigma_{a}, \sigma_{s}$ and $\omega$, are analyzed in terms of diurnal variation, seasonal variation and wind dependence. The overall mean values (and standard deviation) for the entire time period (two years) for $\sigma_{a}$ and $\sigma_{s}$ and $\omega$ are $56 \pm 49 \mathrm{Mm}^{-1}$, $288 \pm 281 \mathrm{Mm}^{-1}$ and $0.80 \pm 0.01$, respectively. The $\omega$ in the urban Beijing surface layer increased from $0.78 \pm 0.11$ in 2005 to $0.82 \pm 0.07$ in 2006 , both lower than the accepted observed $\omega$ range of $0.85-0.95$ in northern hemisphere. Due to the Olympic Games in 2008, the Beijing municipal government introduced some policies to reduce the local emissions. $\sigma_{a}$ is kept constant during these two years even though economic development continued. However, $\sigma_{s}$ still increased (b)

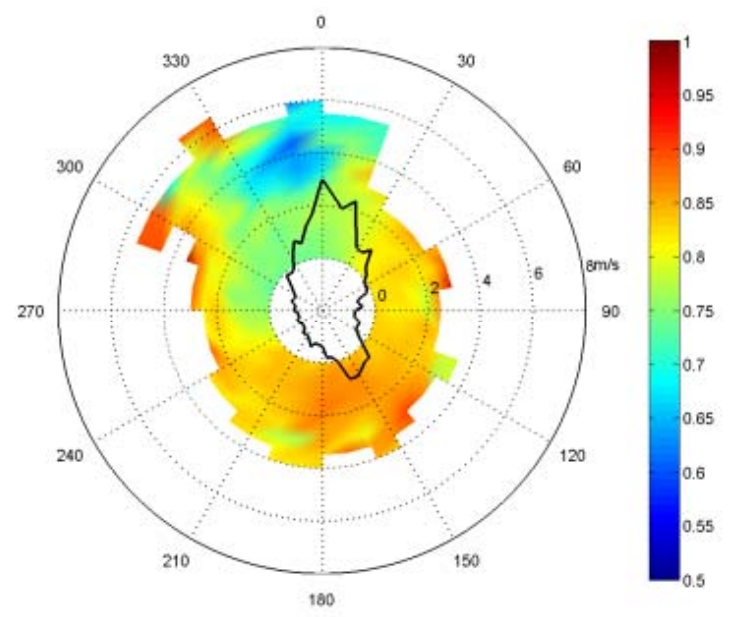

(d)

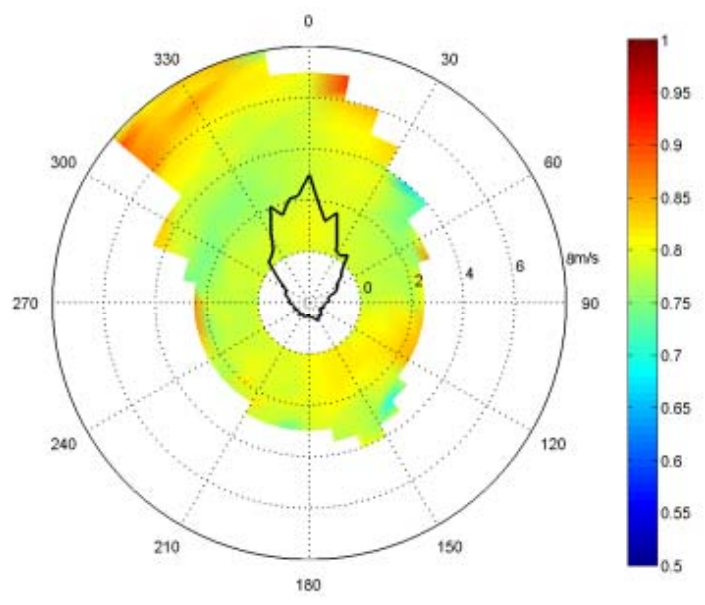

slightly, resulting in an increase of $\omega$. It is obviously still a major challenge for the government to control the secondary particulate pollution, especially pollutants transported into Beijing from a regional locations.

$\sigma_{a}, \sigma_{s}$ and $\omega$ all demonstrated characteristic diurnal variation. $\sigma_{a}$ peaks in the night and is at its lowest value at noon and in the early afternoon. The diurnal pattern of $\sigma_{a}$ is linked both to the evolution of the boundary layer which is unstable in the daytime, and to the direct emission of $\mathrm{BC}$ at night. Generally speaking, the stable boundary layer at night prohibits the dilution of pollutants, while the unstable boundary layer at daytime is beneficial for pollutant dispersion. A key contributor to light absorption is black carbon which is 
mainly emitted from diesel trucks. In Beijing, such trucks are permitted enter the city urban area only during the night hours. $\sigma_{s}$ peaks both around 10:00 and at mid-night. The $\sigma_{s}$ peak in morning may be attributed to large emission of aerosol and gaseous precursors (volatile organic compounds and $\mathrm{NO}_{\mathrm{x}}$ ) in the rush hour. This $\sigma_{s}$ peak in summer and autumn is higher than in spring and winter, and highest in summer. The production of secondary aerosol also contributes to the increasing of $\sigma_{s}$ in summer. $\omega$ peaks around 14:00 and then decrease to a minimum before the sunrise. The diurnal range of $\omega$ in summer $(0.75 \sim 0.85)$ is larger than that in winter $(0.77 \sim 0.83)$, although the minimum in summer appears earlier (05:00) than that in winter (07:00). This diurnal pattern corresponds to the enhancement of the scattering coefficient from late morning and subsequent decrease of the absorption coefficient after the morning.

$\sigma_{a}, \sigma_{s}$ and $\omega$ all show wind dependence. Overall, the $\sigma_{a}$ value is highest when the wind blows from north with a low WS of $0-2 \mathrm{~m} / \mathrm{s}$. This indicates that an emission source may exist not far away from the observation location to the north. From the magnitude of $\sigma_{a}$, we can see that Beijing is mainly governed by local emission sources. Both $\sigma_{a}$ and $\sigma_{s}$ are very low when wind blows from north with high speed and in winter, the highest $\sigma_{a}$ value is higher than in the other three seasons. Coal consumption for heating is considered a major contributor to the high $\sigma_{a}$ value in winter. $\sigma_{s}$ experiences a similar dependence on local wind speed and direction to $\sigma_{a}$ except during the summer. $\sigma_{s}$ has two regions where high values were observed: one is in the north with WS of 0 $2 \mathrm{~m} / \mathrm{s}$ in all seasons except summer (corresponding to local sources), and the other is in the southeast with the WS of 0 $6 \mathrm{~m} / \mathrm{s}$ in summer (local and remote sources). In summer, the $\sigma_{s}$ value is the highest when wind is from southeast with WS of $0-6 \mathrm{~m} / \mathrm{s}$. The southeast wind brings both local emission and regionally transported aerosols to the sample location. This is consistent with some updated studies for summer of Beijing (Garland et al., 2009; Jung et al., 2009). One considerable new finding is the dependence of the scattering coefficients on wind speed and direction and realization that it has very different patterns in seasons other than summer. It is concluded that in summer the air pollution in urban Beijing is attributed to both local emission and regional transports, but in other seasons, the air pollution problem in Beijing is principally due to local emission.

As for $\omega$, the value is higher in the WD sector from $120^{\circ}-$ $180^{\circ}$ with WS of $0-4 \mathrm{~m} / \mathrm{s}$ than the WD sector from $300^{\circ}-$ $360^{\circ}$ with WS of $0-4 \mathrm{~m} / \mathrm{s}$. This may be due to a source or enhancement of absorbing aerosols in the $300-360^{\circ}$ direction. Local sources with severe combustion emissions may be located to the north or northwest of the observation site. Ultimately, this wind dependence indicates that there is a good relationship between wind and aerosol optical properties. It should be considered extremely helpful to take this kind of circular wind map into consideration when emission reduction control policies are formulated.

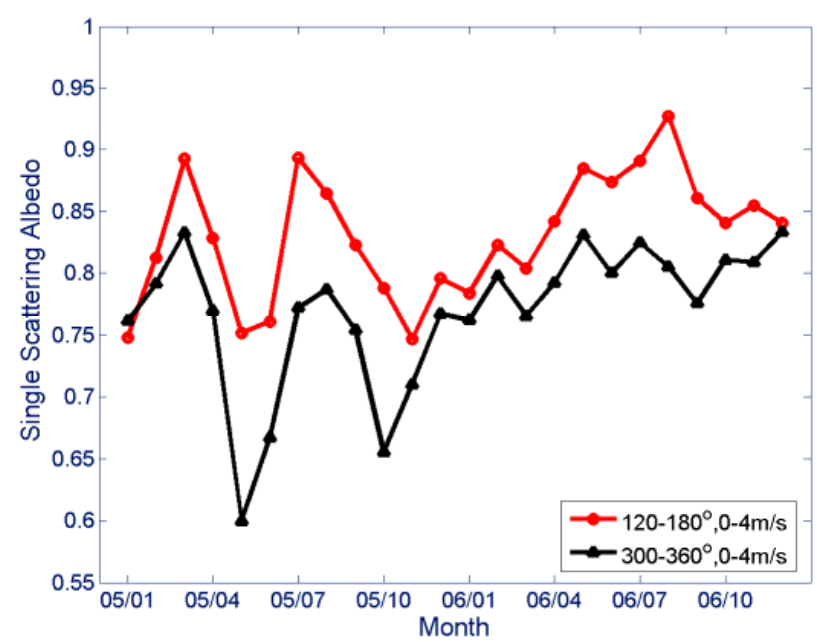

Fig. 8. Monthly mean single scattering albedo in two selected sectors.

Acknowledgements. The authors wish to thank the 3 anonymous reviewers and the editors of this journal for their helpful comments greatly improved this paper. The study is partially supported by the National Natural Science Foundation of China (NSFC) (No. 40575001 and No. 40775002), the National High Technology Research and Development Program of China (863 Major Project, No. 2006AA06A303), and the Knowledge Innovation Program of the Chinese Academy of Sciences (IAP07301).

Edited by: C. K. Chan

\section{References}

Ando, M., Katagiri, K., Tamura, K., et al.: Indoor and outdoor air pollution in Tokyo and Beijing supercities, Atmos. Environ., 30, 695-702, 1994.

Arnott, W. P., Moosmuller, H., Sheridan, P. J., et al.: Photoacoustic and filter-based ambient aerosol light absorption measurements: Instrument comparisons and the role of relative humidity, J. Geophys. Res., 108(D1), 4034, doi:10.1029/2002JD002165, 2003.

Barnard, J. C., Kassianov, E. I., Ackerman, T. P., Johnson, K., Zuberi, B., Molina, L. T., and Molina, M. J.: Estimation of a "radiatively correct" black carbon specific absorption during the Mexico City Metropolitan Area (MCMA) 2003 field campaign, Atmos. Chem. Phys., 7, 1645-1655, 2007, http://www.atmos-chem-phys.net/7/1645/2007/.

Benjamin, G., Jean, C. R., Hélène, C., et al.: Impact of vertical atmospheric structure on Beijing aerosol distribution, Atmos. Environ., 40, 5167-5180, 2006.

Bergin, M. H., Cass, G. R., Xu, J., et al.: Aerosol radiative, physical, and chemical properties in Beijing during June 1999, J. Geophys. Res., 106(D16), 17969-17980, 2001.

Chan, C. K. and Yao, X. H.: Air Pollution in Mega Cities in China - a Review, Atmos. Environ., 42, 1-42. 2008.

Chen, D. S., Cheng, S. Y., Liu, L., Chen, T., et al.: An integrated MM5-CMAQ modeling approach for assessing transboundary $\mathrm{PM}_{10}$ contribution to the host city of 2008 Olympic 
summer games - Beijing, China, Atmos. Environ., 41, 12371250, doi:10.1016/j.atmosenv.2006.09.045, 2007.

Chu, D. A., Kaufman, Y. J., Zibordi, G., Chern, J. D., Mao, J. T., Li, C. C., and Holben, B. N.: Global monitoring of air pollution over land from the Earth Observing System-Terra Moderate Resolution Imaging Spectroradiometer (MODIS), J. Geophys. Res., 108(D21), 4661, doi:10.1029/2002JD003179, 2003.

Comrie, A.: A synoptic climatology of ozone pollution at three forest sites in Pennsylvania, Atmos. Environ., 28, 1601-1614, 1994.

Crutzen, P. J.: New directions: the growing urban heat and pollution "island" effects-impact on chemistry and climate, Atmos. Environ., 38, 3539-3540, 2004.

Eck, T. F., Holben, B. N., Dubovik, O., et al.,: Columnar aerosol optical properties at AERONET sites in central eastern Asia and aerosol transport to the tropical mid-Pacific, J. Geophys. Res., 110, D06202, doi:10.1029/2004JD005274, 2005.

Eder, B., Davis, J. M., Bloomfield, P., et al.: An automated classification scheme designed to better elucidate the dependence of ozone on meteorology, J. Appl. Meteorol., 33, 1182-1199, 1994.

Elminir, H. K.: Dependence of urban air pollutants on meteorology, Sci. Total Environ., 350, 225-237, 2005.

Garland, R. M., Schmid, O., Nowak, A., et al.: Aerosol optical properties observed during Campaign of Air Quality Research in Beijing 2006 (CAREBeijing-2006): Characteristic differences between the inflow and outflow of Beijing city air, J. Geophys. Res., 114, D00G04, doi:10.1029/2008JD010780, 2009.

Hartog, J. J., Hoek, G., Mirme, A., et al.: Relationship between different size classes of particulate matter and meteorology in three European cities, J. Environ. Monitor., 7, 302-310, 2005.

He, K., Yang, F., Ma, Y., et al.: The characteristic of $\mathrm{PM}_{2.5}$ in Beijing, China, Atmos. Environ., 35, 4954-4970, 2001.

IPCC, Intergovernmental Panel on Climate Change: Climate Change, in: The Scientific Basis, edited by: Houghton, J. T., Ding, Y., Griggs, D. J., et al., Cambridge Univ. Press, New York, 2001.

Jacobson, M. Z.: Strong radiative heating due to the mixing state of black carbon in atmospheric aerosols, Nature, 409, 696-697, 2001.

Jung, J., Lee, H., Kim, Y. J., et al.: Optical properties of atmospheric aerosols obtained by in situ and remote measurements during 2006 Campaign of Air Quality Research in Beijing (CAREBeijing-2006), J. Geophys. Res., 114, D00G02, doi:10.1029/2008JD010337, 2009.

Kaiser, D. P. and Qian, Y.: Decreasing trends in sunshine duration over China for 1954-1998: Indication of increased haze pollution?, Geophys. Res. Lett., 29, 2042, doi:10.1029/2002GL016057, 2002.

Kaufman, Y. J., Tanr' e, D., Remer, L. A., Vermote, E. F., Chu, A., and Holben, B. N.: Operational remote sensing of tropospheric aerosol over land from EOS moderate resolution imaging spectroradiometer, J. Geophys. Res., 102(D14), 17051-17067, 1997.

Kaufman, Y. J., Tanr' e, D., and Boucher, O.: A satellite view of aerosols in the climate system, Nature, 419, 215-223, 2002.

Levy, R. C., Remer, L. A., Mattoo, S., Vermote, E. F., and Kaufman, Y. J.: Second-generation operational algorithm: Retrieval of aerosol properties over land from inversion of Moderate Resolution Imaging Spectroradiometer spectral reflectance, J. Geophys. Res., 112, D13211, doi:10.1029/2006JD007811, 2007.

Li, C., Marufu, L. T., Dickerson, R. R., et al.: In situ measurements of trace gases and aerosol optical properties at a rural site in northern China during East Asian Study of Tropospheric Aerosols: An International Regional Experiment 2005, J. Geophys. Res., 112, D22S04, doi:10.1029/2006JD007592, 2007.

Li, C. C., Mao, J. T., Lau, A. K., et al.: Research on the air pollution in Beijing and Surroundings with MODIA AOD products, Chinese J. Atmos. Sci., 27, 869-880, 2003.

Li, X. W., Zhou, X. J., and Li, W. L.: The cooling of Sichuan Province in recent 40 years and its probable mechanisms, Acta Meteorol. Sin., 9, 57-68, 1995.

Luo, Y. F., Lu, D., Zhou, X., et al.: Characteristics of the spatial distribution and yearly variation of aerosol optical depth over China in last 30 years, J. Geophys. Res., 106(D13), 1450114513, 2001.

Mao, J. T. and Li, C. C.: Observation Study of Aerosol Radiative Properties over China, Acta Meteorol. Sin., 20, 306-320, 2006.

Malm, W. C. and Day, D. E.: Estimates of aerosol species scattering characteristics as a function of relative humidity, Atmos. Environ., 35, 2845-2860, 2001.

Menon, S., Hansen, J., Nazarenko, L., and Luo, Y. F.: Climate effects of black carbon aerosols in China and India, Science, 297, 2250-2253, 2002.

Moosmuller, H., Arnott, W. P., Rogers, C. F., et al.: Photoacoustic and filter measurements related to aerosol light absorption during the Northern Front Range Air Quality Study (Colorado 1996/1997), J. Geophys. Res., 103(D21), 28149-28157, 1998.

Müller, D., Teche, M., Eichler, H., et al.: Strong particle light absorption over the Pearl River Delta (south China) and Beijing (north China) determined from combined Raman lidar and Sun photometer observations, J. Geophys. Res., 33, L20811, doi:10.1029/2006GL027196, 2006.

Nessler, R., Weingartner, E. and Baltensperger, U.: Effect of humidity on aerosol light absorption and its implications for extinction and the single scattering albedo illustrated for a site in the lower troposphere, J. Aerosol Sci., 36, 958-972, 2005.

Penner, J. E., Dong, X. Q., and Chen, Y.: Observational evidence of a change in radiative forcing due to the indirect aerosol effect, Nature, 427, 231-234, 2001.

Pinxteren, V., Brüggemann, D. E., Gnauk, T., et al.: Sizeand time-resolved chemical particle characterization during CAREBeijing-2006: Different pollution regimes and diurnal profiles, J. Geophys. Res., 114, D00G09, doi:10.1029/2008JD010890, 2009.

Qian, Y. and Giorgi, F.: Regional climatic effects of anthropogenic aerosols? The case of southwestern China, Geophys. Res. Lett., 27, 3521-3524, 2000.

Qiu, J., Yang, L., and Zhang, X.: Characteristics of the imaginary part and single-scattering albedo of urban aerosols in northern China, Tellus, 56(B), 276-284, 2004.

Ramachandran, S. and Rajesh, T. A.: Black carbon aerosol mass concentration over Ahmedabad, an urban location in western India: Comparison with urban sites in Asia, Europe, Canada, and the United States, J. Geophys. Res., 112, D06211, doi:10.1029/2006JD007488, 2007.

Ramanathan, V., Crutzen, P. J., Kiehl, J. T., and Rosenfeld, D.: Aerosols, climate, and the hydrological cycle, Science, 294, 2119-2124, 2001a.

Ramanathan, V., Crutzen, P. J., Lelieveld, J., et al.: Indian Ocean Experiment: An integrated analysis of the climate forcing and 
effects of the great Indo-Asian haze, J. Geophys. Res., 106(D22), 28371-28398, 2001b.

Silvia, E. D.: Aerosol impacts on visible light extinction in the atmosphere of Mexico City, Sci. Total Environ., 287, 213-220, 2002.

Shi, Z., Shao, L., Jones, T. P., et al.: Characterization of airborne individual particles collected in an urban area, a satellite city and a clean air area in Beijing, Atmos. Environ., 37, 4097-4108, 2003.

Streets, D. G., Fu, J. S., Jang, C. J., et al.: Air quality during the 2008 Beijing Olympic Games, Atmos. Environ., 41, 480-492, doi:10.1016/j.atmosenv.2006.08.046, 2007.

Takegawa, N., Miyakawa, T., Kuwata, M., et al.: Variability of submicron aerosol observed at a rural site in Beijing in the summer of 2006, J. Geophys. Res., 114, D00G05, doi:10.1029/2008JD010857, 2009.
Xia, X. A., Chen, H. B., Wang, P. C., et al.: Variation of columnintegrated aerosol properties in a Chinese urban region, J. Geophys. Res., 111, D05204, doi:10.1029/2005JD006203, 2006.

Yan, P., Tang, J., Huang, J., Mao, J. T., Zhou, X.J., Liu, Q., Wang, Z. F., and Zhou, H. G.: The measurement of aerosol optical properties at a rural site in Northern China, Atmos. Chem. Phys., 8, 2229-2242, 2008, http://www.atmos-chem-phys.net/8/2229/2008/.

Yan, P., Pan, X., Tang, J., et al.: Hygroscopic growth of aerosol scattering coefficient: A comparative analysis between urban and suburban sites at winter in Beijing, Particuology, 7, 52-60, 2009.

Zhang, Y., Shao, L., Tang, K., et al.: The study of urban photochemical smog pollution, Acta Scientiarum Naturalium Universitatis Pekinensis, 34, 392-400, 1998.

Zhou, L. M., Dickinson, R. E., Tian, Y. H., et al.: Evidence for a significant urbanization effect on climate in China, P. Natl. Acad. Sci., 101(26), 9540-9544, 2004. 